\title{
Influencing Factors on Consumers' Willingness to Share Energy Data on Online Energy Platforms
}

\author{
Claudia Maier ${ }^{1}$, Christian Pfeiffer ${ }^{1}$, Stefanie Hatzl $^{2} \&$ Eva Flei ${ }^{2}$
}

${ }^{1}$ Forschung Burgenland, Eisenstadt, Austria

${ }^{2}$ University of Graz, Graz, Austria

Correspondence: Claudia Maier, Forschung Burgenland, Eisenstadt Austria. ORCID ID: https://orcid.org/0000-00021227-8443 E-mail: claudia.maier@forschung-burgenland.at

\author{
Received: February 26, 2021 \\ Accepted: March 27, 2021 \\ Online Published: April 25, 2021 \\ doi:10.11114/bms.v7i2.5161 \\ URL: https://doi.org/10.11114/bms.v7i2.5161
}

\begin{abstract}
Climate change requires an adaptation of the energy system towards an efficient use of renewable energies. For efficient control and optimization of the energy system, energy consumption and production data at household level play an essential role. Sharing platforms can enable the bundling and controlling of energy data from individual households. However, there is often a lack of acceptance among potential users to share their own data on such platforms. Therefore, this paper investigates the willingness of consumers to share their personal energy data. In particular, several factors that influence this willingness are examined. Decisive for the willingness are incentives for consumers in return for sharing their energy data. These can be offered in personal added value or collective added value. This paper shows that the factors perceived behavioral control, personal attitude and subjective norm have an influence on the willingness of private users to share energy data if a personal benefit or a collective benefit is provided. The age of users and their privacy concerns affect the willingness to share only in case personal value is added. These findings are valuable for the development and operation of online energy platforms.
\end{abstract}

Keywords: online energy platform, energy data, data sharing, energy consumption optimization

\section{Introduction}

The decarbonization of the energy system and the transition to a renewable, decentralized energy supply requires sociotechnical system changes. This refers to technological innovations, but also to necessary behavioral changes (Geels, 2018). In this context, the increasing trend of digitalization and the diffusion of smart technologies can be usefully exploited to achieve corresponding national climate targets (BMNT, 2018; Ford, Stephenson, Stiehler \& Brown, 2014). This includes, for example, the promotion of digital sector coupling, the development of digital services or the increase of energy efficiency (BMNT, 2019). Digital technologies such as cloud computing, digital platforms, and smart devices (Cao et al., 2016; Rehman \& Batool, 2015) enable individuals to share their data with others (Huang et al., 2015). In this context, shared consumer data is of economic value to companies (Zhao \& Xue, 2013). To increase the consumers' willingness to share personal data, sharing platforms serve as peer-to-peer networks. These create added value for all participants in a co-creation approach (Grönroos, 2008; Richter \& Slowinski, 2019).

Smart technologies that generate temporal energy data open up a wide range of opportunities in this area. Energy data as a relevant resource for the provision of energy services in data-driven business models has gained economic importance (Camarinha Matos, 2016; Visser, 2015). These can be shared and exchanged on web-based sharing platforms. New technologies to promote energy-efficient behavior of consumers require information sharing and data transfer among different stakeholders. However, such disclosure of data on sharing platforms is not widely accepted by consumers (Fogg, 2002).

This paper presents the results of the GEL-OpenDataPlatform project. In the project, a web-based sharing platform is developed to enable consumers to easily access and better understand relevant energy data. It also aims to support behavioral change and positively influences consumers' attitudes towards energy efficiency (Hamari, Koivisto \& Pakkanen, 2014). 
The platform is to be understood as a means for sharing and exchanging data, whereby consumption data from consumers is required. In view of all regulations on data protection, this data must be voluntarily exchanged. Previous studies show that individuals are concerned about, among other things, the secure handling of their data and privacy (Chen et al., 2017). In addition, the issue is viewed differently from consumer to consumer and further influencing factors are considered relevant to explain the willingness to share data. Nevertheless, there is a general need for research to understand the willingness to share data (Silva, Karnouskos \& Ilic, 2012). In particular, there is a lack of empirical studies in the context of sharing platforms in the energy sector. Thus, the objective of the paper is twofold: First, this paper aims to examine the reason for sharing energy data by distinguishing between an individual and a collective added value. Second, this paper investigates the factors that determine consumers' willingness to share energy data on online energy platforms. With the information about predictors, sharing platform developers can use the examined factors as a guide to design their platforms based on user needs and therefore, increase users' interaction and data exchange on it. Eventually, the broader use of such platforms promotes more efficient energy consumption and supports the vision of a sustainable energy system transition.

\section{Literature Review}

Data sharing in the context of the climate change challenge is needed to establish a sustainable decentralized energy system. In order to integrate renewable energy sources and generate system efficiency and optimization, it is not only necessary to have an energy flow between production, distribution and consumption, but also to exchange information data (Daki, El Hannani, Aqqal, Haidine \& Dahbi, 2017). Currently, studies explicitly targeting the sharing of energy data on digital platforms are scarce. The report on consumers' views on sharing half-hourly billing data from the UK regulator Ofgem (2018) shows that energy consumption data is perceived as the least sensitive data type compared to other personal data. Moreover, the study shows that almost half of consumers are willing to share their energy data if it is linked to benefits (e.g., financial savings, improved energy efficiency).

However, consumers' acceptance of new technologies such as web-based energy sharing platforms is not excessively high (Fogg, 2002). A problem to be considered is that individuals often lack trust in actors, such as energy supply companies, regarding the adoption of smart technologies (Chen, Xu \& Arpan, 2017). Especially, if benefits for individuals are not visible, their acceptance of such new concepts is low (Kollmann \& Moser, 2014).

Findings on data sharing in general show that various factors influence consumers' willingness to share personal data (Schudy \& Utikal, 2017; Sayogo \& Pardo, 2012). Benefits for users can be a motivation to share data. These benefits can, for example, be financial if the need for monetary rewards is relevant for users (Anic et al., 2018). Besides monetary rewards, individuals can profit from information transparency that is achieved on an energy data sharing platform. Information tailored to the household supports residents in their efforts to use resources in a more efficient way and therefore reduce energy consumption on household level (Jetzek, Avital \& Bjørn-Andersen, 2014). However, especially in the paradigms of the sharing economy/society or open data movements, which are characterized by online platforms and communities, collective benefits and collective action also play an essential role (Hamari, Sjöklint \& Ukkonen, 2016). In contrast to an individual benefit, a collective benefit helps the public at large, for example, by enabling access to certain information that is valuable for a community (Hamari et al., 2016), by supporting research or free software development (Ziefle, Halbey \& Kowalewski, 2016). Information technologies such as sharing platforms enable network mechanisms to promote behaviors that create collective value, going beyond traditional market-based mechanisms of value generation. In the context of energy consumption, the perceived collective benefit is to contribute to energy efficiency at the system level and to create sustainable value by sharing energy data that reduces information asymmetry regarding resource allocation in a smart grid (Jetzek et al., 2014).

Tschersich et al. (2016) examined the difference between personal benefits for users themselves and collective benefits for others in the context of data sharing. In their study, the willingness to share data is highest if personal benefits are provided in return. In contrast, the study results of Ziefle et al. (2016) show that collective benefits provide a stronger incentive for consumers to share information. In order to create individualized benefits, the provider must know certain personal information about the recipient in advance. This requirement, which may be a deterrent for some customers, does not apply to the provision of collective benefits. Based on the unclear results of previous studies, the following hypothesis is formed in a first step.

Hypothesis 1 (H1): The willingness to share energy data differs between the incentive of a personal and a collective added value.

For this paper, the distinction between personal and collective added value forms the basis for the investigation of consumers' willingness to share their personal energy data. The hypotheses generated in the following are directed towards each the personal and the collective added value for consumers in order to determine the different effects of the two types of benefits on the willingness to share energy data. 
As a well-founded basic theory concerning the behavioral intention of consumers, the theory of planned behavior (TPB) is applied to the willingness to share energy data. The intention to act, which is typically explained in this theory, is seen as an indicator for actions that are actually to be taken. Accordingly, the intention to set a certain behavior - in the present case: to share energy data - is determined by three influencing variables: Attitude, subjective norms, and perceived behavioral control (Ajzen, 1991).

The personal attitude of private users toward a platform has an influence on their intention to share data. There is a positive correlation between consumers' attitudes towards social media and their willingness to share data on these platforms (Taddicken, 2014). In the context of energy consumption, the study by Kranz, Gallenkamp and Picot (2010) show that the attitude of homeowners towards smart meters is crucial for their voluntary willingness to install them. Thus, consumers are more willing to provide their personal data if they have a positive attitude towards the purpose of the provision. Accordingly, the following hypotheses are formulated with reference to individual and collective added value.

Hypothesis $2 a$ (H2a): The more positive the attitude towards an online energy platform, the higher the willingness to share energy data for a personal added value.

Hypothesis $2 b(H 2 b)$ : The more positive the attitude towards an online energy platform, the higher the willingness to share energy data for a collective added value.

Furthermore, this paper considers the subjective norm related to the willingness to share energy data. The study by Markos, Milne and Peltier (2017) indicates that consumers rate the risk of sharing financial data as high as the risk of sharing information in the course of interactions in a community. Consumers are thus very sensitive to data that affect their public image. Their willingness to share data that has a negative impact on their reputation is accordingly low. In this context, Hargittai \& Marwick (2016) and Taddicken (2014) show that individuals are more likely to share their information on public online platforms (e.g., social media platforms) if the information is of high social relevance to their stakeholders or their community. Therefore, for individuals with a high subjective norm, the provision of added value for others is of particular importance. Subjective norm may also play a role in sharing energy data. Considering the investigated incentives for added value, the following hypotheses are therefore formed.

Hypothesis $3 a(H 3 a)$ : The higher the subjective norm for users, the higher the willingness to share energy data for a personal added value.

Hypothesis $3 b(H 3 b)$ : The higher the subjective norm for users, the higher the willingness to share energy data for a collective added value.

Additionally, a trusted platform that conveys a sense of control over shared data is crucial for or against sharing personal data (Cao et al., 2016; Anic et al., 2018). Kranz et al. (2010) show that perceived control over the functions of smart meters in a household increases residents' acceptance of this monitoring technology. This subsequently increases the willingness to install smart meters. Perceived behavioral control has not yet been studied in conjunction with the type of value added (personal or collective) in the context of sharing energy data. This leads to the following hypotheses.

Hypothesis $4 a(\mathrm{H} 4 a)$ : The higher the perceived behavioral control of users, the higher the willingness to share energy data for a personal added value.

Hypothesis $4 b$ (H4b): The higher the perceived behavioral control of users, the higher the willingness to share energy data for a collective added value.

In addition to the factors borrowed from the TPB, several studies show that another determinant for the willingness to share energy data is the risk perception of consumers when sharing information publicly (Markos et al., 2017; Cao et al., 2016; Anic et al., 2018). The more privacy concerns are present, the less willing consumers are to share information. On the one hand, such concerns can be addressed by collecting data on a trusted platform and by platform operators being transparent about how data is handled (Cao et al., 2016). The trustworthiness of a website is crucial to decrease consumers' privacy concerns towards it. For this purpose, providing transparency about privacy rights is beneficial (Anic et al., 2018). On the other hand, privacy concerns can be mitigated with the provision of benefits (Anic et al., 2018). It is known that consumers who are generally more willing to share their personal information have fewer privacy concerns (Taddicken, 2014). These findings are now tested by subsequent hypotheses regarding the different incentives of personal and collective added value.

Hypothesis $5 a$ (H5a): The lower the privacy concerns of consumers, the higher the willingness to share energy data for a personal added value.

Hypothesis $5 b(H 5 b)$ : The lower the privacy concerns of consumers, the higher the willingness to share energy data for a collective added value.

A final aspect that influences the willingness to share energy data is age. There is a difference on how people from different 
age groups use the internet and how they perceive online privacy. Younger adults use social networks significantly more intensive than middle-aged and older adults do. Furthermore, older adults put more effort into protecting their data on the internet compared to younger persons (Zeissig, Lidynia, Vervier, Gadeib \& Ziefle, 2017). According to Markos et al. (2017), younger people are more willing to share data with others than older people are. In addition, younger individuals are more likely to be persuaded by personalized benefits, as they are generally less apprehensive about disclosing personal information (Markos et al., 2017; Lee, Wong, Oh \& Chang, 2019). An experiment, conducted by Walrave, Poels, Antheunis, Van den Broeck and van Noort (2016), supports these findings. Adolescents prefer high-personalized advertising, which is generated based on their social media behavior and preferences, to medium- or low-personalized advertising. To test this in relation to energy data sharing, the following hypotheses are formed.

Hypothesis $6 a(H 6 a)$ : The younger the consumers, the higher their willingness to share energy data for a personal added value.

Hypothesis $6 b(H 6 b)$ : The younger the consumers, the greater the willingness to share energy data for a collective added value.

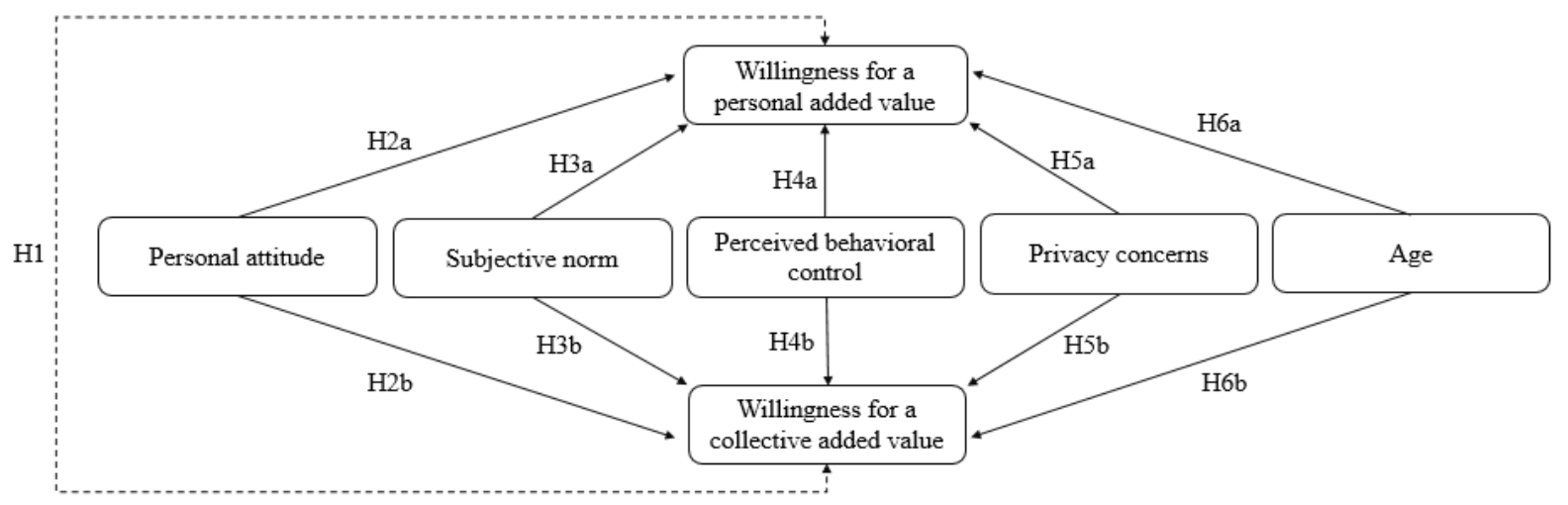

Figure 1. Hypothesis model on the willingness to share energy data

The hypothesis model in Figure 1 summarizes the hypotheses that have been formulated and visually depicts the connections between the individual factors.

\section{Method}

In order to test the postulated hypotheses empirically, a postal survey was conducted in a climate and energy model region in northern Burgenland in Austria.

\subsection{Research Design}

The survey was conducted in December 2019 and January 2020. The climate and energy model region in Burgenland encompasses 8,351 households in eight municipalities (Statistics Austria, 2019). The "last-birthday method" (Salmon \& Nichols, 1983) was used for sampling. Thereby, the person in the household with at least 16 years of age, who had his or her last birthday, filled out the questionnaire. A total of $\mathrm{n}=548$ persons participated in the survey. With a given response rate of $6.56 \%$, a sampling error of $3.40 \%$ is to be expected.

The questionnaire consisted of the thematic areas of (i) willingness to share energy data, (ii) factors influencing willingness to share energy data, and (iii) socio-demographic characteristics. The questionnaire was prefaced with a brief description of an online energy platform (OEP). Respondents were provided with information that such an OEP offers private households the opportunity to share energy data anonymously and on a voluntary basis. Examples were given to clarify the term "energy data," such as the electricity consumption of a washing machine or a stove. In addition, the benefits of an OEP were described. These include the possibility of receiving individually tailored recommendations on how to save energy, or to compare one's own electricity consumption with that of other households.

To measure the willingness to share energy data, scale constructs were adopted that had already been used in previous studies. All questionnaire items were adapted to OEPs in the context of sharing energy data. Five response options were given for all statements, with higher values indicating higher agreement (see Table 1). On the one hand, the "willingness for a personal added value" scale captures the consumers' willingness to share energy data if they receive a personal benefit or useful services in return. On the other hand, the "willingness for a collective added value" addresses the benefits or services from sharing one's own energy data for others. Both scales were adapted from Tschersich et al. (2016). The questionnaire also included items to measure "privacy concerns", for which items were used from Lee et al. (2019). The scale constructs for the TPB were drawn from Cho, Chen and Chung (2010) and adapted to the context of sharing energy 
data. These include "perceived behavioral control" when interacting on an OEP, respondents' "personal attitudes" towards data sharing, and the "subjective norm" which captures the view of opinion leaders on the topic of data sharing. Finally, the sociodemographic characteristics gender, age, level of education and household size were queried.

\subsection{Sample Description}

The participants of the survey are on average 56.04 years old $(\mathrm{SD}=15.11) .57 .84 \%$ are male and $42.16 \%$ are female. In terms of educational level, $57.89 \%$ reported not having a high school diploma, while $26.90 \%$ have a one and $15.20 \%$ have a university degree. The typical household consists of two persons (50.19\%). 14.34\% reported living alone, $16.04 \%$ live in three-person households. There are also households with four or more people (19.43\%).

To fulfill representativeness, the sample was weighted using the standard integrated EU-SILC design (Osier, Museux, Seoane \& Verma, 2006), as indicated in formula (1).

$$
1 / C \leq\left(q_{i j k} / q_{. j}\right)\left(w_{i j k} / w_{. j}\right) /\left(d_{i j k} / d_{. j .}\right) \leq C,
$$

where $C$ is a constant trim value (set to $C=4.50$ ) to constrain extreme values to more acceptable weights, $q$ is the nonresponse correction, $w$ is the calibration by age, gender, and education level, and $d$ corresponds to the design weights, respectively for observation $i=1, \ldots, \mathrm{n}_{\mathrm{j}}$ from community $j=1, \ldots, 8$ and household size $k=1, \ldots, 4$ as design characteristic.

For each constructed scale, which comprised three to four items, means were computed. Scale reliability is consistently acceptable $(\alpha>0.70)$ and therefore the scale constructs can be used for further analysis (see Table 1).

\section{Results}

In this section, the results of the study and the hypothesis testing are analyzed and presented.

\subsection{Descriptive Analysis}

Respondents show moderate willingness to share energy data if they would receive a personal added value like a general benefit or useful services $(\mathrm{M}=3.04, \mathrm{SD}=1.29)$. A similar result is observed with respect to willingness to share their energy data to receive a collective added value $(\mathrm{M}=2.90, \mathrm{SD}=1.27)$. In comparison, the willingness to share energy data is slightly higher for a personal added value than for a collective added value. Personal attitudes toward sharing energy data on an OEP are below average $(\mathrm{M}=2.79, \mathrm{SD}=1.39)$. In addition, respondents tend to be less convinced that sharing their energy data is endorsed by their peers. Their subjective norm tends to be low $(\mathrm{M}=2.51, \mathrm{SD}=1.06)$. The respondents' perceived behavioral control has a moderate mean value of $3.19(\mathrm{SD}=1.14)$. Thus, respondents are not entirely sure about their control of the data they share on an OEP. A comparatively high mean value is found for privacy concerns $(\mathrm{M}=3.84, \mathrm{SD}=1.09)$. Respondents are thus more concerned about sharing information or providing personal data (e.g., for the purpose of registration) on the internet. Privacy issues in general and potential misuse of password or identity information are also part of this rather wide-ranging privacy concern. 
Table 1. Analysis of scale construction and descriptive statistics

\begin{tabular}{|c|c|c|c|}
\hline Scale $^{1,2}$ & Items $^{2}$ & $\alpha^{3}$ & $\mathrm{M}^{4}(\mathrm{SD})^{5}$ \\
\hline $\begin{array}{l}\text { Willingness for a } \\
\text { personal added } \\
\text { value }\end{array}$ & $\begin{array}{l}\text { In general, I would be willing to share energy data on an } \mathrm{OEP}^{6} \text { if I can profit } \\
\text { from it. } \\
\text { I would be willing to share energy data on an OEP if it provides useful } \\
\text { services for me. } \\
\text { If I see a benefit for myself, I would in general be willing to share energy } \\
\text { data on an OEP. }\end{array}$ & 0.95 & $3.04(1.29)$ \\
\hline $\begin{array}{l}\text { Willingness for a } \\
\text { collective added } \\
\text { value }\end{array}$ & $\begin{array}{l}\text { In general, I would be willing to share energy data on an OEP if other people } \\
\text { could profit from it. } \\
\text { I would be willing to share energy data on an OEP if it provides other people } \\
\text { with useful services. } \\
\text { If I see a benefit for other people, I would in general be willing to share } \\
\text { energy data on an OEP. }\end{array}$ & 0.96 & $2.90(1.27)$ \\
\hline Personal attitude & $\begin{array}{l}\text { Sharing energy data on an OEP would be... } \\
\text { Very unpleasant ... very pleasant } \\
\text { Very bad ... very good } \\
\text { Very worthless ... very valuable } \\
\text { Very harmful ... very beneficial }\end{array}$ & 0.95 & $2.79(1.39)$ \\
\hline Subjective norm & $\begin{array}{l}\text { People who are important to me think I should contribute to an OEP by } \\
\text { sharing energy data. } \\
\text { People who are important to me would share their energy data. } \\
\text { People who can influence me think I should share my energy data. }\end{array}$ & 0.89 & $2.51(1.06)$ \\
\hline $\begin{array}{l}\text { Perceived } \\
\text { behavioral control }\end{array}$ & $\begin{array}{l}\text { It makes a difference whether I share my energy data on an OEP. } \\
\text { Sharing energy-data on an OEP is entirely in my control. } \\
\text { I am confident in my ability to share energy data on an OEP. }\end{array}$ & 0.76 & 3.19 (1.14) \\
\hline Privacy concerns & $\begin{array}{l}\text { I am concerned about submitting information on the Internet because of } \\
\text { what others might do with it. } \\
\text { I am concerned that web sites require too much personal information for } \\
\text { registration. } \\
\text { I am concerned that someone may use my ID and password illegally. } \\
\text { In general, I am concerned about my privacy when I use the Internet. }\end{array}$ & 0.89 & $3.84(1.09)$ \\
\hline
\end{tabular}

\footnotetext{
${ }^{1} \mathrm{n}$ between 429 and $548 ;{ }^{2}$ expression $1=$ does not apply at all, $5=$ fully applies

${ }^{3}$ Cronbach's $\alpha$-values for scale reliability; ${ }^{4}$ mean; ${ }^{5}$ standard deviation

${ }^{6}$ The abbreviation OEP is used according to the questionnaire: online energy platform.

Table 1 shows the single items that were used for the scale construction, the reliability (Cronbach's $\alpha$ ) of the constructs, as well as the mean values and their standard deviations.
} 


\subsection{Hypothesis Testing}

To test $H 1$, a two-sided T-test was conducted to compare willingness to share energy data for a personal added value and for a collective added value. A significant difference was found $(\mathrm{t}(431)=3.67, \mathrm{p}<0.01)$. However, the difference in users' willingness to share energy data is very small in terms of different benefits $(\mathrm{d}=0.17)$. Thus, $H 1$ is supported with a very small effect.

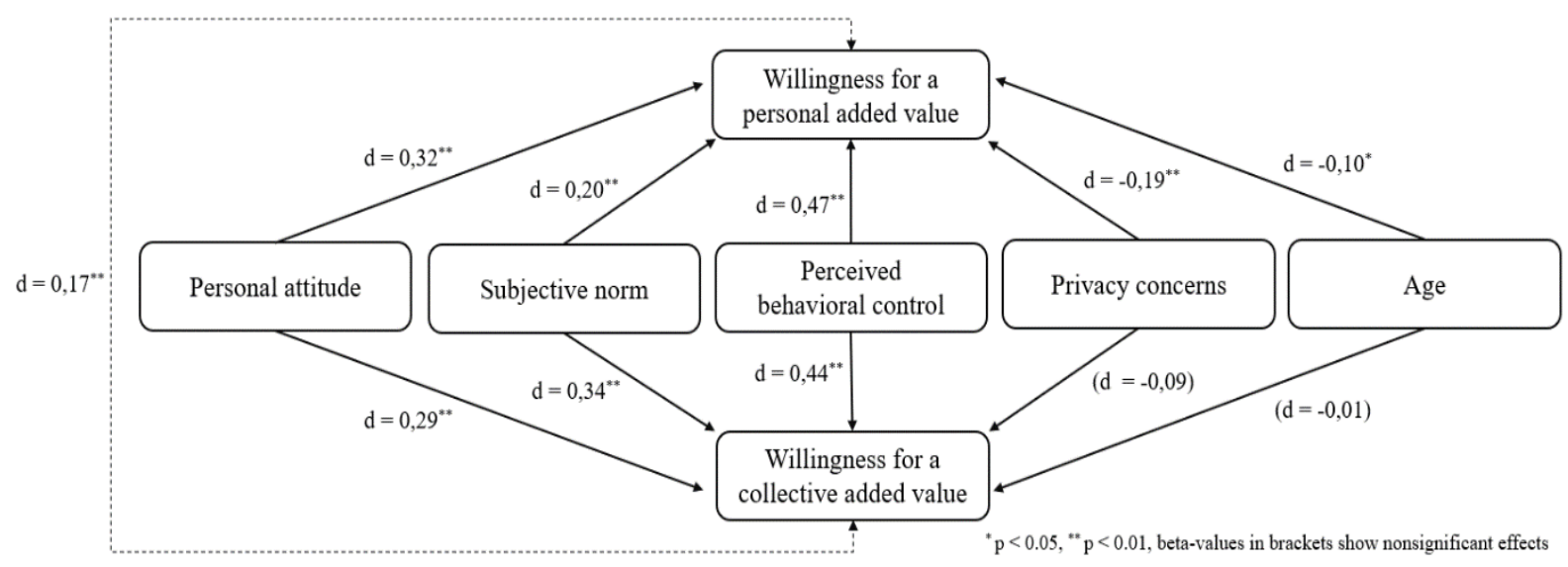

Figure 2. Hypothesis testing

Figure 2 shows the results of the hypotheses tests. To test $H 2$ to $H 6$, multiple linear regression models were calculated with each of the constructs linked to the willingness to share energy data (Figure 2). Both the model explaining willingness for a personal added value $\left(\mathrm{R}_{\text {adj }}{ }=0.68\right)$ as well as that explaining willingness for a collective added value $\left(\mathrm{R}^{2}{ }_{\text {adj }}=0.71\right)$ show high quality of fit.

$H 2 a$ and $H 2 b$ address personal attitudes towards OEPs and their impact on willingness to share energy data. A significant effect on willingness was found for both a personal added value $(\beta=0.26, p<0.01, d=0.32)$ and a collective added value $(\beta=0.22, p<0.001, d=0.29)$. The more positive the attitude towards an OEP, the more willing users are to share energy data on it, for both a personal and a collective added value. Thus, $H 2 a$ and $H 2 b$ are supported with a small effect.

Next, $H 3 a$ and $H 3 b$ were tested. These consider the influence of the subjective norm on the willingness to share energy data. Here, a small, significant influence of the subjective norm on the willingness to share energy data could be derived for a personal added value $(\beta=0.17, p<0.01, d=0.20)$ as well as for a collective added value $(\beta=0.29, p<0.01, d=$ 0.34). The higher the subjective norm of the consumers, the higher their willingness to share energy data for a personal and a collective added value. Therefore, $H 3 a$ and $H 3 b$ are supported.

In $H 4 a$ and $H 4 b$, the influence of perceived behavioral control on willingness to share energy data is addressed. Here, a significant influence was found on both willingness if personal value is added $(\beta=0.47, \mathrm{p}<0.01, \mathrm{~d}=0.47)$ and willingness if collective value is added $(\beta=0.42, \mathrm{p}<0.01, \mathrm{~d}=0.44)$. Perceived behavioral control has a weak to moderate effect on willingness to share energy data in both cases. Thus, both $H 4 a$ and $H 4 b$ are supported.

$H 5 a$ and $H 5 b$ examined the impact of respondents' privacy concerns on their willingness to share energy data for both a personal and a collective added value. Again, a negative influence of privacy concerns on willingness was found for both cases. Privacy concerns have a significant influence on willingness for a personal added value $(\beta=-0.11, p<0.01, d=$ $0.19)$. The lower the privacy concerns, the higher the willingness to share one's energy data when a personal value is added. The influence of privacy concerns on willingness for a collective added value is not significant $(\beta=0.05, p=0.07)$. Thus, $H 5 a$ can be supported with a small effect. In contrast, there is not enough evidence to support $H 5 b$.

Finally, $H 6 a$ and $H 6 b$ address the influence of age on the willingness to share energy data for a personal and a collective added value. In both cases, a negative correlation between age and willingness to share energy data was found. While age has a significant influence on willingness for a personal added value $(\beta=-0.06, p=0.04, d=-0.10)$, the influence on willingness for a collective added value is not significant $(\beta=-0.01, p=0.87)$. Thus, the younger the consumers, the higher the willingness to share their own energy data for a personal added value. Although the observed effect is very small, there is still evidence to support $H 6 a$. In contrast, $H 6 b$ is not supported.

\section{Discussion and Conclusion}

This study investigates the willingness of private individuals in a climate and energy model region in Burgenland in Austria to share energy data on an OEP. The focus is on the differences in the provision of a personal added value and a 
collective added value and further influencing factors.

The participants in the study generally have rather high privacy concerns regarding the disclosure of personal information on the internet. However, if they see added value in sharing data, these concerns can be neutralized. There is a distinction in terms of the type of added value. Participants perceive a small difference between the incentive of a personal added value and a collective added value they receive in return for sharing energy data. Therefore, it is recommended for operators of an OEP to evaluate exactly what kind of added value should be provided for the target group to be addressed in order to design an OEP accordingly. The personalization of incentives requires users to share personal information with OEP operators in advance (Ziefle et al., 2016). Such individualized benefits are more likely for younger users to increase their willingness to share energy data. In addition, if people who have few privacy concerns comprise the target group, personalized added value in return for sharing energy data should be provided. In this case, contrary to collective added value, personal added value has a weak but demonstrable influence on consumers' willingness to share energy data.

Regardless of whether potential users of an OEP have low or high privacy concerns, it is highly relevant to provide a platform that allows them a certain degree of behavioral control. The higher the perceived behavioral control of users when acting on an OEP, the higher is their willingness to share energy data on it. This applies for both a personal and a collective added value. Perceived behavioral control has the largest effect on the willingness to share energy data in this study. Transparent handling of the shared data by the platform operators gives users the opportunity to control what data they share and what happens to their personal data. On the one hand, this creates trust; on the other hand, it increases the willingness to share data (Cao et al., 2016; Anic et al., 2018). Similar is the situation with personal attitudes towards an OEP. A platform that builds trust and towards which users have a positive attitude can be crucial for sharing energy data on it. This is independent of whether the added value for sharing data is personal or collective. Another important determinant is the consumers' subjective norm. The higher the social relevance, the more willing consumers are to share their energy data with others if they create added value for society in return, but also if they receive personal benefits as a result. Thus, people who generally share information for social networking are an important target group for operators of OEPs.

To conclude, it is relevant for developers and operators of OEPs to form a transparent and trustworthy platform and to segment potential users to elicit which type of added value increases their willingness to share energy data the most. The use of OEPs can help consumers to change their consumption behavior in a sustainable manner, which eventually is a significant contribution to climate protection.

\section{Acknowledgements}

This project is supported with the funds from the Climate and Energy Fund and implemented in the framework of the RTI-initiative "Flagship region Energy".

\section{References}

Ajzen, I. (1991). The theory of planned behaviour. Organizational Behavior and Human Decision Processes, 50, 179211.

Anic, I.-D., Budak, J., Rajh, E., Recher, V., Skare, V., \& Skrinjaric, B. (2018). Extended model of online privacy concern: what drives consumers' decisions? Online Information Review. https://doi.org/10.1108/OIR-10-2017-0281

BMNT. (2019). Bundesministerium für Nachhaltigkeit und Tourismus (2019). Integrierter nationaler Energie- und Klimaplan für Österreich. Periode 2021-2030. Wien: BMNT.

BMNT. (2018). Bundesministerium für Nachhaltigkeit und Tourismus (2018). Energie in Österreich 2018: Zahlen, Daten, Fakten. Wien: BMNT.

Camarinha Matos, L. M. (2016). Collaborative smart grids - A survey on trends. Renewable and Sustainable Energy Reviews, 65, 283-294. https://doi.org/10.1016/j.rser.2016.06.093

Cao, Q. H., Khan, I., Farahbakhsh, R., Madhusudan, G., Lee, G. M., \& Crespi, N. (2016). A trust model for data sharing in smart cities. 2016 IEEE International Conference on Communications (ICC), 1-7. https://doi.org/10.1109/ICC.2016.7510834

Chen, C.-f., Xu, X., \& Arpan, L. (2017). Between the technology acceptance model and sustainable energy technology acceptance model: Investigating smart meter acceptance in the United States. Energy Research \& Social Science, 25, 93-104. https://doi.org/10.1016/j.erss.2016.12.011

Cho, H., Chen, M., \& Chung, S. (2010). Testing an Integrative Theoretical Model of Knowledge-Sharing Behavior in the Context of Wikipedia. Journal of the American Society for Information Science and Technology, 61(6), 1198-1212. https://doi.org/10.1002/asi.21316 
Daki, H., El Hannani, A., Aqqal, A., Haidine, A., \& Dahbi, A. (2017). Big Data management in smart grid: concepts, requirements and implementation. Journal of Big Data, 4(1), 1-19. https://doi.org/10.1186/s40537-017-0070-y

Fogg, B. J. (2002). Persuasive Technology - Using Computers to Change What We Think and Do. Ubiquity, 6137(5), 89120. https://doi.org/10.1145/764008.763957

Ford, R., Stephenson, J., Stiehler, W., \& Brown, N. (2014). Energy Transitions: Home Energy Management Sytems (HEMS). Centre for Sustainability, University of Otago. Retrieved from http://hdl.handle.net/10523/4788

Geels, F. W. (2018). Disruption and low-carbon system transformation: Progress and new challenges in socio-technical transitions research and the Multi-Level perspective. Energy Research \& Social Science, 37, 224-231. https://doi.org/10.1016/j.erss.2017.10.010

Grönroos, C. (2008). Service logic revisited: who creates value? And who co-creates? European Business Review, 20(4), 298-314. https://doi.org/10.1108/09555340810886585

Hamari, J., Koivisto, J., \& Pakkanen, T. (2014). Do Persuasive Technologies Persuade? - A Review of Empirical Studies. Proceedings of 9th International Conference, PERSUASIVE, 2014, 21-23. https://doi.org/10.1007/978-3-319-07127$5 \_11$

Hamari, J., Sjöklint, M., \& Ukkonen, A. (2016). The sharing economy: Why people participate in collaborative consumption. Journal of the Association for Information Science and Technology, 67(9), 2047-2059. https://doi.org/10.1002/asi.23552

Hargittai, E., \& Marwick, A. (2016). What can I really do? Explaining the privacy paradox with online apathy. International journal of communication, 10, 21.

Huang, X., Liu, J. K., Tang, S., Xiang, Y., Liang, K., Xu, L., \& Zhou, J. (2015). Cost-Effective Authentic and Anonymous Data Sharing with Forward Security. IEEE Transactions on Computers, 64/6. https://doi.org/10.1109/TC.2014.2315619

Jetzek, T., Avital, M., \& Bjørn-Andersen, N. (2014). Generating Sustainable Value from Open Data in a Sharing Society. In B. Bergvall-Kåreborn, \& P. A. Nielsen (Eds.), Creating Value for All Through IT (pp. 62-82). Springer Science+Business Media. IFIP AICT - Advances in Information and Communication technology, 429. https://doi.org/10.1007/978-3-662-43459-8

Kollmann, A., \& Moser, S. (2014). Smart Metering im Kontext von Smart Grids. Berichte aus Energie- und Umweltforschung, 6. Wien: bmvit.

Kranz, J., Gallenkamp, J., \& Picot, A. (2010). Power Control to the People? Private Consumers' Acceptance of Smart Meters. ECIS 2010 Proceedings, 96.

Lee, H., Wong, S. F., Oh, J., \& Chang, Y. (2019). Information privacy concerns and demographic characteristics: Data from a Korean media panel survey. Governmental Information Quarterly, 36, 294-303. https://doi.org/10.1016/j.giq.2019.01.002

Markos, E., Milne, G. R., \& Peltier, J. W. (2017). Information Sensitivity and Willingess to Provide Continua: A Comparative Privacy Study of the United States and Brazil. Journal of Public Policy \& Marketing, 36(1), 79-96. https://doi.org/10.1509/jppm.15.159

Ofgem. (2018). Consumer views on sharing half-hourly settlement data. Research report. London: Ofgem. Retrieved from https://www.ofgem.gov.uk/system/files/docs/2018/07/consumer_views_on_sharing_hhs_data_1.pdf

Osier, G., Museux, J.-M., Seoane, P., \& Verma, V. (2006). Cross-sectional and longitudinal weighting for the EU-SILC rotational design. Retrieved from https:/www.iser.essex.ac.uk/files/survey/ulsc/methodological-research/mols2006/scientific-social-programme/papers/Osier.pdf, access on 02.09.2020.

Rehman, M. H., \& Batool, A. (2015). Pattern-based Data Sharing in Big Data Environments. Digital Technologies, 1, 3942. https://doi:10.12691/dt-1-1-8

Richter, H., \& Slowinski, P. R. (2019). The Data Sharing Economy: On the Emergence of New Intermediaries. IIC, 50, 4-29. https://doi.org/10.1007/s40319-018-00777-7

Salmon, C., \& Nichols, J. S. (1983). The Next-Birthday Method of Respondent Selection. Public Opinion Quarterly, 47, 270-276. https://doi.org/10.1086/268785

Sayogo, D. S., \& Pardo, T. A. (2012). Exploring the Motive for Data Publication in Open Data Initiative: Linking Intention to Action. 45th Hawaii International Conference on System Sciences, Maui, HI, 2623-2632. https://doi: 10.1109/HICSS.2012.271 
Schudy, S., \& Utikal, V. (2017). You must not know about me - On the willingness to share personal data. Journal of Economic Behavior \& Organization, 141, 1-13. https://doi.org/10.1016/j.jebo.2017.05.023

Silva, P. G. D., Karnouskos, S., \& Ilic, D. (2012). A survey towards understanding residential prosumers in smart grid neighbourhoods. Proceedings of 3rd IEEE PES ISGT Europe, 14-17, Oct. 2012. https://doi:10.1109/ISGTEurope.2012.6465864

Statistics Austria. (2019). Register-based Labour Market Statistics 2017 - Households and Families. Retrieved from http://www.statistik.at/blickgem/

Taddicken, M. (2014). The 'Privacy Paradox' in the Social Web: The Impact of Privacy Concerns, Individual Characteristics, and the Perceived Social Relevance on Different Forms of Self-Disclosure. J. of Computer-Mediated Comm, 19(2), 248-273. https://doi.org/10.1111/jcc4.12052

Tschersich, M., Kiyomoto, S., Pape, S., Nakamura, T., Bal, G., Takasaki, H., \& Rannenberg, K. (2016). On Gender Specific Perception of Data Sharing in Japan. J.-H. Hoepmann \& S. Katenbeisser (Hrsg.), SEC 2016, IFIP AICT 471, 150-160. https://doi.org/10.1007/978-3-319-33630-5_11

Visser, J. V. G. (2015). Barriers in open energy data: An exploratory study into open energy data barriers and their mitigation strategies (master's hesis). Delft University of Technology.

Walrave, M., Poels, K., Antheunis, M. L., Van den Broeck, E., \& van Noort, G. (2018). Like or dislike? Adolescents' responses to personalized social network site advertising. Journal of Marketing Communications, 24(6), 599-616. http://dx.doi.org/10.1080/13527266.2016.1182938

Zeissig, E. M., Lidynia, C., Vervier, L., Gadeib, A., \& Ziefle, M. (2017). Online privacy perceptions of older adults. International Conference on Human Aspects of IT for the Aged Population, 181-200, Springer, Cham. https://doi.org/10.1007/978-3-319-58536-9_16

Zhao, X., \& Xue, L. (2013). Competitive target advertising and consumer data sharing. Journal of Management Information Systems, 29(3), 189-222. https://doi.org/10.2753/MIS0742-1222290306

Ziefle, M., Halbey, J., \& Kowalewski, S. (2016). Users' Willingness to Share Data on the Internet: Perceived Benefits and Caveats. IoTBD, 255-265. https://doi.org/10.5220/0005897402550265

\section{Copyrights}

Copyright for this article is retained by the author(s), with first publication rights granted to the journal.

This is an open-access article distributed under the terms and conditions of the Creative Commons Attribution license which permits unrestricted use, distribution, and reproduction in any medium, provided the original work is properly cited. 